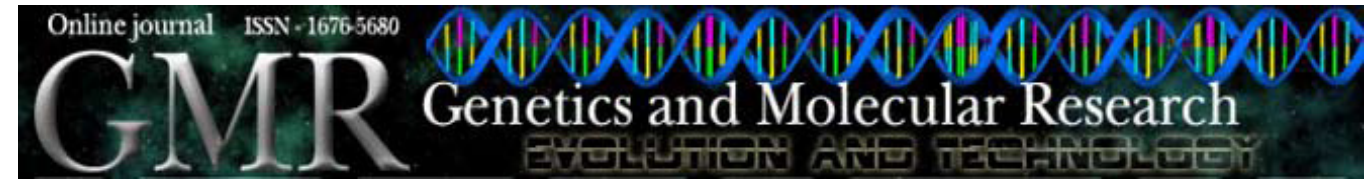

\title{
Allelic variability in the third intron of the fibroin light chain gene in Bombyx mori (Lepidoptera: Bombycidae)
}

\author{
J.F. Barbosa, J.P. Bravo, D.B. Zanatta, J.L.C. Silva and M.A. Fernandez \\ Departamento de Biologia Celular e Genética, \\ Universidade Estadual de Maringá, Maringá, PR, Brasil \\ Corresponding author: M.A. Fernandez \\ E-mail: aparecidafernandez@gmail.com
}

Genet. Mol. Res. 8 (1): 197-206 (2009)

Received October 10, 2008

Accepted November 27, 2008

Published February 25, 2009

\begin{abstract}
Conformation-sensitive gel electrophoresis is a useful method for identifying allele polymorphism; it provides co-dominant molecular markers. Using this method, we identified genetic variability in the third intron of the fibroin light chain gene, fib-L, in six Bombyx mori strains. Only Chinese C21A strain did not demonstrate allelic alterations, showing only homoduplex DNA molecules. We found distinct heteroduplex profiles in the Japanese HAA, M12B and M19-2 and the Chinese C25B and C242 strains. Analysis with restriction endonuclease fingerprinting conformation-sensitive gel electrophoresis demonstrated the potential of this method for the identification of allelic variability in B. mori; this was confirmed by cloning and sequencing the different alleles. The main alteration was a 12-bp deletion in two alleles of the C24-2 strain and one allele of the HAA strain; this deletion results in specific heteroduplex DNA molecule profiles.
\end{abstract}

Key words: Conformation-sensitive gel electrophoresis; Allelic variability; Bombyx mori; Silkworm; Fibroin light chain 


\section{INTRODUCTION}

The silkworm Bombyx mori L. belongs to the second largest order of insects, the Lepidoptera, which contains more than 140,000 species. This taxonomic group is highly diversified and includes some of the more destructive agricultural pests (Reagan and Flynn, 1986), as well as many insects used for economic production, such as B. mori. This silkworm is economically important due to its large contribution to the silk industry in many countries around the world. During its domestication history, thousands of $B$. mori strains have been developed and maintained (Goldsmith et al., 2005). Research on silkworm larval development and its applications is important for silk production and could improve the amount and quality of silk thread produced commercially (Li et al., 2005). Silk fibroin is secreted into the lumen of the posterior silk gland of the B. mori silkworm and is composed mainly of three polypeptides: a $350-\mathrm{kDa}$ heavy chain (Ohmachi et al., 1982), a 26-kDa light chain (Yamaguchi et al., 1989; Kikuchi et al., 1992) and fibrohexamerin (Inoue et al., 2000). The fibroin light chain gene, fib- $L$, is located on chromosome 14 and consists of 14,626 bp, containing seven exons with large-sized introns (Kikuchi et al., 1992). The first intron occupies about $60 \%$ of this gene and the other introns together occupy approximately $31 \%$, such that $91 \%$ of the gene is composed of non-coding DNA.

Several methods are used in studies of the genetic variability of B. mori strains (Li et al., 2005). Of these, conformation-sensitive gel electrophoresis (CSGE) has made it possible to identify thirteen polymorphic markers in known genes of B. mori (Yasukochi, 1998). CSGE is a useful method for the identification of allelic variability and is capable of detecting nucleotide substitutions and small deletions with the great advantage of generating co-dominant molecular markers. In this method, DNA is amplified by polymerase chain reaction (PCR), and the resultant products are denatured and renatured. In this process, different molecules can be formed by the combination of the DNA strands of heterozygote alleles: two homoduplex DNA molecules with perfect complementarity among the strains (wild with wild and mutant with mutant) and heteroduplex DNA molecules that result from the mixture of alleles that contain nucleotide changes (Ganguly et al., 1993; Ganguly, 2002). The analysis of the heteroduplex molecules can be carried out by gel electrophoresis under denaturing conditions (Ganguly et al., 1993; Ganguly, 2002) and by capillary electrophoresis (Velasco et al., 2007).

DNA sequencing is also a great strategy for studying the mutations that can cause disease or significant alterations in phenotypes, and it is capable of discovering all variants of DNA, except for extensive changes/deletions. Sequencing of genes with many of mutations distributed along the fragment analyzed is particularly labor-intensive and expensive, and most of the time it cannot be performed because the allelic mutation results in fragments of the same size but different sequences. Therefore, it is essential to establish strategies and simple and reproducible methods to detect allelic variability (Velasco et al., 2007). Restriction endonuclease fingerprinting with CSGE (REF-CSGE) is an easy and low-cost screening for the identification of allelic variability without sequencing (Herzog et al., 2002).

The study of the genetic variability in the fib- $L$ third intron is interesting because the $N d-s$ and $N d-s^{D}$ mutations were previously described in this segment, and these mutations are characterized by a deletion located downstream of exon III, which causes 
the recombination of a specific region of this intron with further downstream sequences (Takei et al., 1987; Mori et al., 1995). This deletion occurs within the third intron after a sequence of $16 \mathrm{bp}$ that were found to be duplicated in the mutants. The $N d$-s mutant was initially identified in one specific strain of B. mori in 1960, and the $N d-s^{D}$ mutant was obtained after injection of diethyl sulfate into a male pupa of a normal B. mori of unknown strain and subsequently identified in the progeny of the fourth generation (Gamo and Sato, 1985). These mutants are characterized by an immature posterior silk gland and less than $1 \%$ of the normal secretion level of fibroin, and they produce a very thin, naked-pupa cocoon that consists mostly of sericin (Mori et al., 1995). Allelic variability in this segment could contribute clues to understanding the involvement of specific sequences in the recombination processes that occur in the fib- $L$ gene.

The results for the third intron of the $B$. mori fib- $L$ gene strains presented in this study suggest the existence of different profiles of heteroduplex DNA molecules, and different alleles were cloned and sequenced, showing the variability between the strains. In addition, CSGE analysis combined with REF (REF-CSGE) proved to be a potential method for the identification of the allelic variability profile in this silkworm.

\section{MATERIAL AND METHODS}

\section{Material}

The B. mori strains belong to Universidade Estadual de Maringá (UEM) and Associação dos Criadores da Seda de Nova Esperança e Regiões Sericícolas do Paraná (ACESP) in Brazil. The strains analyzed in this study were the Japanese HAA, M19-2 and M12B and Chinese C25B, C24-2 and C21A strains. All strains received the same nutritional and rearing treatments.

\section{DNA extraction}

For the silkworm HAA, the genomic DNA of three individuals was extracted from silk glands of 5th-instar larvae. For the other strains, the DNA was extracted from the 1stinstar larval pool. The extraction protocol previously described by Mills and Goldsmith (2000) was used with modifications. The pairs of silk glands from the HAA strains were dissected and incubated in $3 \mathrm{~mL}$ extraction buffer (1.5\% sarcosyl, $50 \mathrm{mM}$ EDTA, $\mathrm{pH} 8.0$, $10 \mathrm{mM} \mathrm{NaCl}$ and $1 \mathrm{mg} / \mathrm{mL}$ proteinase $\mathrm{K}$ ) for $2-3 \mathrm{~h}$ at $50^{\circ} \mathrm{C}$. The larval pool samples were pulverized in liquid nitrogen and incubated with extraction buffer for $2-3 \mathrm{~h}$ at $50^{\circ} \mathrm{C}$. The DNA was purified by extraction with $24: 1$ chloroform and isoamyl alcohol and three extractions with phenol, $\mathrm{pH}$ 8.0. The DNA was precipitated with 0.7 volumes of isopropyl alcohol and $0.2 \mathrm{M} \mathrm{NaCl}$. The DNA pellet was dissolved in TE buffer (10 mM Tris-HCl, 1 mM EDTA, $\mathrm{pH}$ 8.0) with RNase $(10 \mu \mathrm{g} / \mathrm{mL})$. The concentration of DNA was determined at $260 \mathrm{~nm}$ in a spectrophotometer.

\section{CSGE analysis}

The primers for the amplification of the third intron of the fib- $L$ gene 
(5'-ACGTCGATGGGACTACGTCG-3' and 5'-CGGACCTGACGCCGTCTGTG-3') were designed with the FAST-PCR software (version 3.5.30 of Ruslan Kalendar). The sequences were complementary to the end of the third exon and the beginning of the fourth exon, respectively (Figure 1). PCR was accomplished in a final volume of $15 \mu \mathrm{L}$, with $2.5 \mathrm{mM}$ dNTPs, $100 \mathrm{ng}$ DNA, 25 pmol of each primer, $1 \mathrm{X}$ PCR buffer (with $1.5 \mathrm{mM} \mathrm{MgCl}_{2}$ ) and 1 unit Taq Polymerase (Invitrogen). The amplification conditions were 35 cycles of $1 \mathrm{~min}$ at $94^{\circ} \mathrm{C}, 1 \mathrm{~min}$ at $58^{\circ} \mathrm{C}$ for annealing, $1 \mathrm{~min}$ at $72^{\circ} \mathrm{C}$ and a final extension of $10 \mathrm{~min}$ at $72^{\circ} \mathrm{C}$. The 900 -bp product was detected by $1 \%$ agarose gel electrophoresis in $1 \mathrm{X}$ TBE buffer (45 mM Tris-borate, $1 \mathrm{mM}$ EDTA, $\mathrm{pH} 8.0$ ) at $3.5 \mathrm{~V} / \mathrm{cm}$ at room temperature.

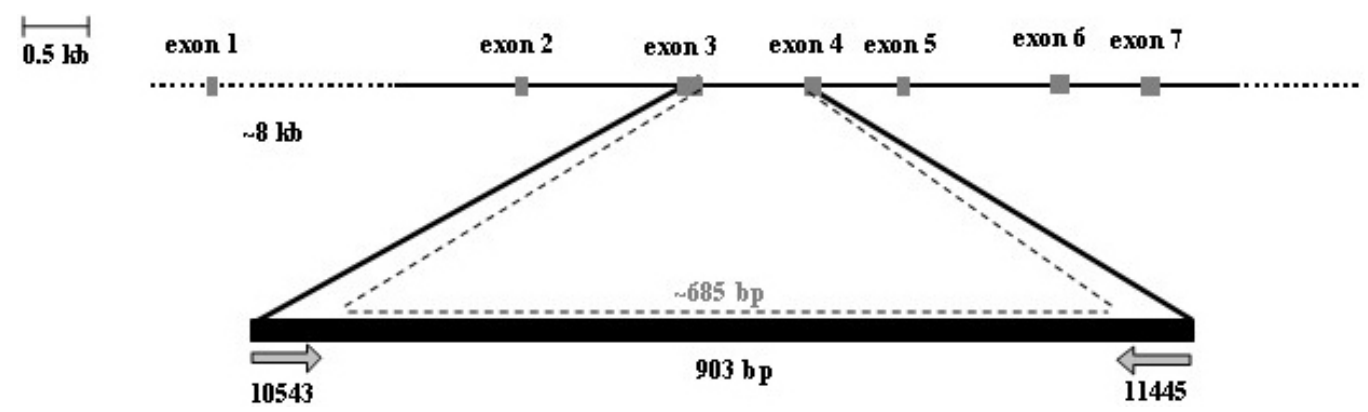

Figure 1. Map of 14,478 bp of the $f i b-L$ gene. The amplified segment of the third intron of $903 \mathrm{bp}$ and the analyzed segment of $\sim 685 \mathrm{bp}$ are indicated.

To analyze homoduplex and heteroduplex DNA molecules, the PCR products were denatured at $95^{\circ} \mathrm{C}$ for $10 \mathrm{~min}$ and renatured at $60^{\circ} \mathrm{C}$ for $60 \mathrm{~min}$. Before electrophoresis, 4 $\mu \mathrm{L}$ of the samples was mixed with $4 \mu \mathrm{L}$ of loading buffer (20 ethylene glycol, 30 formamide, 0.025 xylene cyanol and $0.025 \%$ bromophenol blue). The CSGE gel was prepared with a solution of $40 \%$ acrylamide (39.6 g acrylamide and $0.4 \mathrm{~g}$ 1,4-bis(acryloyl)piperazine in $100 \mathrm{~mL}$ ). The running buffer was $0.5 \mathrm{X}$ TTE (43.04 $\mathrm{g}$ Tris- $\mathrm{HCl}, 14.24 \mathrm{~g}$ taurine and $0.28 \mathrm{~g}$ EDTA in $130 \mathrm{~mL}, \mathrm{pH} 9.0$ ). The gel was submitted to a pre-running at $200 \mathrm{~V}$ for 1 $\mathrm{h}$, and electrophoresis was carried out at $250 \mathrm{~V}$ for $16 \mathrm{~h}$ at room temperature. The DNA was stained with $0.1 \mathrm{mg} / \mathrm{mL}$ ethidium bromide in water and photo-documented under a UV light with a UVP system (BioImaging System).

\section{REF-CSGE analysis}

To validate the profiles of the heteroduplex molecules observed in this study, the PCR products of three strains with polymorphic alleles, M12B, HAAi2 (specimen 2) and C24-2, were submitted to cleavage with the restriction enzyme $K p n I$. The restriction fragments were analyzed by CSGE. After electrophoresis, the gel was stained with $0.1 \mathrm{mg} / \mathrm{mL}$ ethidium bromide and photo-documented as described above. 


\section{Cloning, sequencing and sequence analysis}

The PCR products of the M12B, HAAi2 and C24-2 B. mori strains were purified with the QIAquick PCR Purification Kit (Qiagen) and cloned with the PCR Cloning Kit (Qiagen) into the pDrive plasmid. Sequencing of the four recombinant clones of each strain was performed using the DYEnamic ET Dye Terminator Kit (Amersham Biosciences) with the forward and reverse primers. The reactions were conducted in an automatic DNA MegaBACE 1000 sequencer (Amersham Biosciences), and the sequences obtained were analyzed with the ClustalW software (EMBL-EBI).

\section{RESULTS AND DISCUSSION}

CSGE and REF-CSGE analyses showed homoduplex and heteroduplex DNA molecules in the third intron of the $f i b-L$ gene of the $B$. mori strains.

The CSGE method is reproducible, sensitive and specific, which makes the detection of nucleotide alterations easier and reveals polymorphisms among individuals with fidelity of the results. This method identifies different alleles through heteroduplex DNA molecules represented as co-dominant markers, avoiding false-positive interpretations. CSGE has been used with great success in several polymorphism studies (Finnilä et al., 2000; Lahti et al., 2004; Krawczynski et al., 2004; Karppinen et al., 2006), and in the detection of specific mutations (Vianello et al., 2002; Körkkö et al., 2002; Sundaresan et al., 2007). The sensitivity of CSGE has already been described and discussed in several works, and its application in polymorphism identification among individuals results in more than 90\% fidelity (Ganguly et al., 1993; Ganguly, 2002). In B. mori, Yasukochi (1998) described 13 polymorphic markers with CSGE in several genes from C108 and p50 silkworm strains. For fib-L, they reported polymorphism by urea-agarose gel electrophoresis and the results were used for linkage analysis.

In this study, we investigated the third intron of the fib- $L$ in six B. mori strains from the germplasm bank of UEM/ACESP with the objective of identifying variability and differentiating these strains genetically. CSGE analysis detected allelic variability in the 903-bp PCR product of the B. mori third intron of the fib- $L$ gene. The first analysis was accomplished with three specimens of the strain HAA, and only specimen 2 (HAAi2) showed heteroduplex DNA molecules (Figure 2). For the other five strains, the analysis was made with the 1st-instar larval pool samples (Figure 3). The results also indicated that only the C21A strain did not display allelic variability. The majority of the analyses were carried out with 1st-instar larval pool samples because the goal was not to lose any of the heteroduplex DNA molecules in each strain population. Although HAA specimen 2 showed a CSGE profile with heteroduplex DNA molecules, it is possible that more molecules could be detected with a population sample from this strain.

The strains showed more than one CSGE profile for heteroduplex DNA molecules. One profile showed more than two heteroduplex DNA molecules and included the Japanese strains HAA, M19-2 and M12B. Another profile showed only two heteroduplex DNA molecules and included the Chinese strains C24-2 and C25B.

To test if it is possible to characterize the intron analyzed here by REF-CSGE, the PCR products of the strains C24-2, HAAi2 and M12B were submitted to KpnI cleavage to 


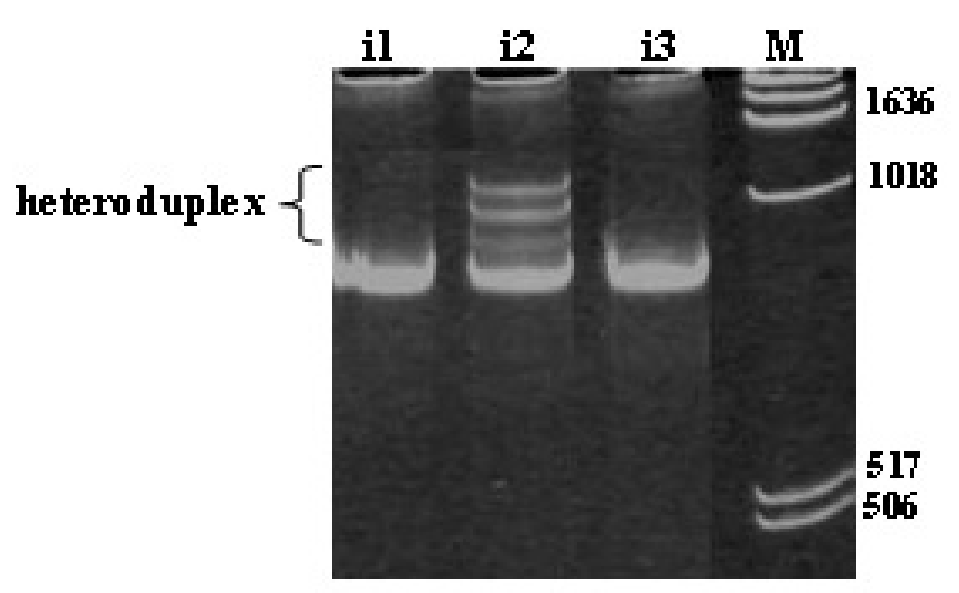

Figure 2. Conformation-sensitive gel electrophoresis analyses of the Bombyx mori fib- $L$ gene third intron from three specimens (i1, i2 and i3) of the Japanese HAA strain. Specimen 2 is the only one that shows heteroduplex DNA molecules. $\mathrm{M}=1-\mathrm{kb}$ ladder DNA molecular weight marker (Invitrogen).

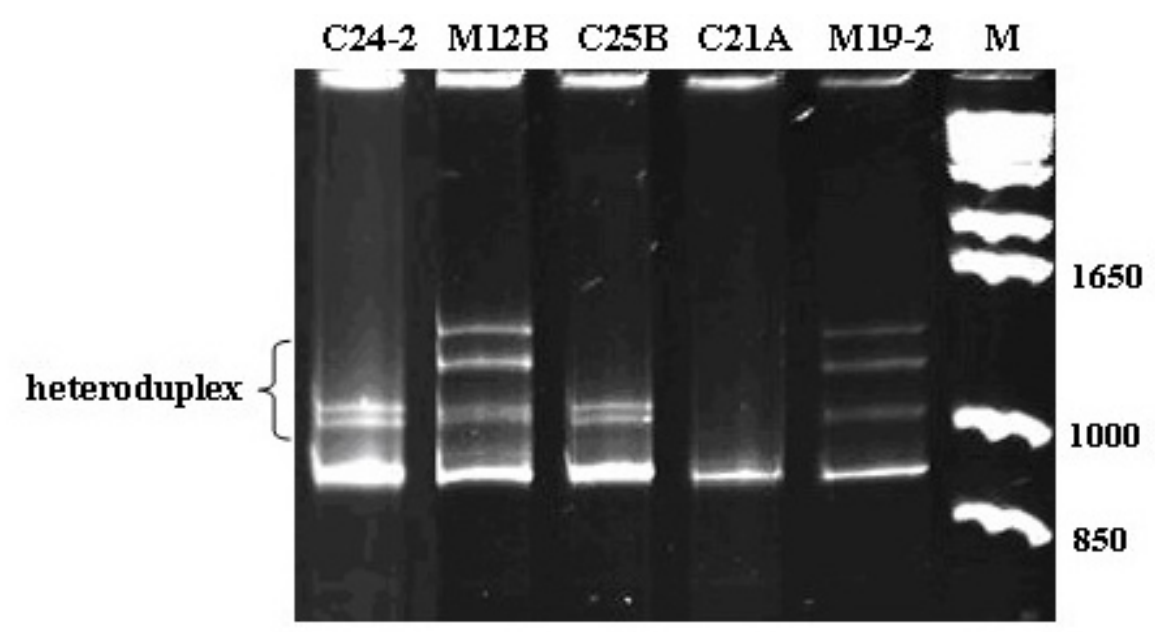

Figure 3. Conformation-sensitive gel electrophoresis analyses of the Bombyx mori fib- $L$ gene third intron of the C24-2, M12B, C25B, C21A, and M19-2 strains. There are two profiles of the heteroduplex DNA molecules. The profile with two heteroduplex DNA molecules was observed for the Chinese C24-2 and C25B strains; the profile with more than two heteroduplex DNA molecules can be observed in the Japanese M12B and M19-2 strains. The Chinese C21A strain is the only one that did not show conformation-sensitive gel electrophoresis heteroduplex DNA molecules. $\mathrm{M}=1-\mathrm{kb}$ ladder plus DNA molecular weight marker (Invitrogen).

compare the REF-CSGE heteroduplex DNA molecules. The results showed that the third intron of the $f i b-L$ gene of the $B$. mori strains analyzed displayed specific heteroduplex DNA molecules in REF-CSGE, which could be a useful tool for analysis of silkworm variability in this chromosomal segment. Figure 4 shows the results from the cleavage of the amplified 
products from the M12B, C24-2 and HAAi2 strains. It is clear that the M12B segment has a mixture of the heteroduplex DNA molecules, as observed in the other two strains. The heteroduplex DNA molecules obtained from the M12B analysis are similar to those observed with the larger fragment (600 bp) from C24-2, and the DNA heteroduplex molecules resulting from the 300-bp fragment are similar to those observed in the HAA strain.

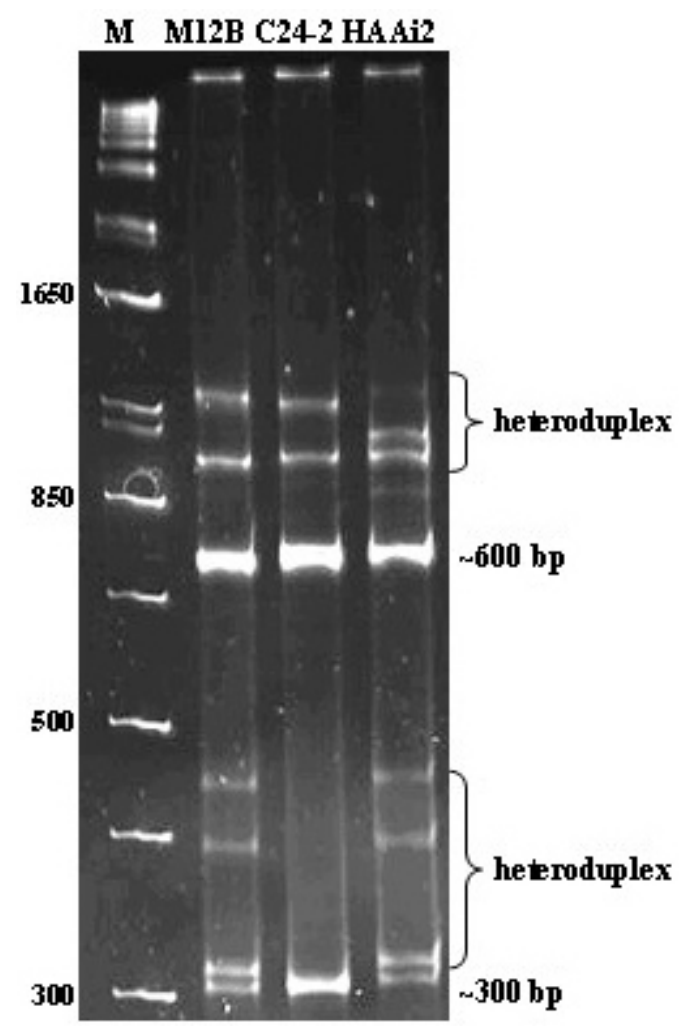

Figure 4. Restriction endonuclease fingerprinting with conformation-sensitive gel electrophoresis analyses of the Bombyx mori fib- $L$ gene third intron of the M12B, C24-2 and HAAi2 strains. The amplified product was cleaved with $\mathrm{KpnI}$. The homoduplex DNA molecules are the fragments with $\sim 300$ and $\sim 600 \mathrm{bp}$, respectively. The heteroduplex DNA molecules from each fragment characterize the conformation-sensitive gel electrophoresis profile. $\mathrm{M}=1-\mathrm{kb}$ ladder plus DNA molecular weight marker (Invitrogen).

\section{Sequence analysis showed gene allelic variability and conserved segments for the silkworm third intron $f i b-L$}

To determine the nucleotide variability responsible for the CSGE profiles, among the clones sequenced, two alleles (a1 and a2) from the strains HAAi2 and C24-2, and one allele from M12B were examined. A ClustalW alignment with sequences from M76430 (Japanese strain) and AY026058 (Chinese strain) is shown in Figure 5. HAAi2a1 showed a 12-bp dele- 
tion (positions 10,796 to 10,807). This sequence was also found to be deleted in AY026058 and in the two alleles of the C24-2 strain. This is the main significant alteration observed in the 300-bp KpnI fragment and could be responsible for the heteroduplex DNA molecules observed in this fragment in the DNA of strains M12B and HAAi2 (Figure 4). It is clear that heteroduplex DNA molecules were not observed for the 300-bp fragment from strain C24-2, because the 12-bp sequence was deleted in the two allele sequences of this strain (Figure 5).

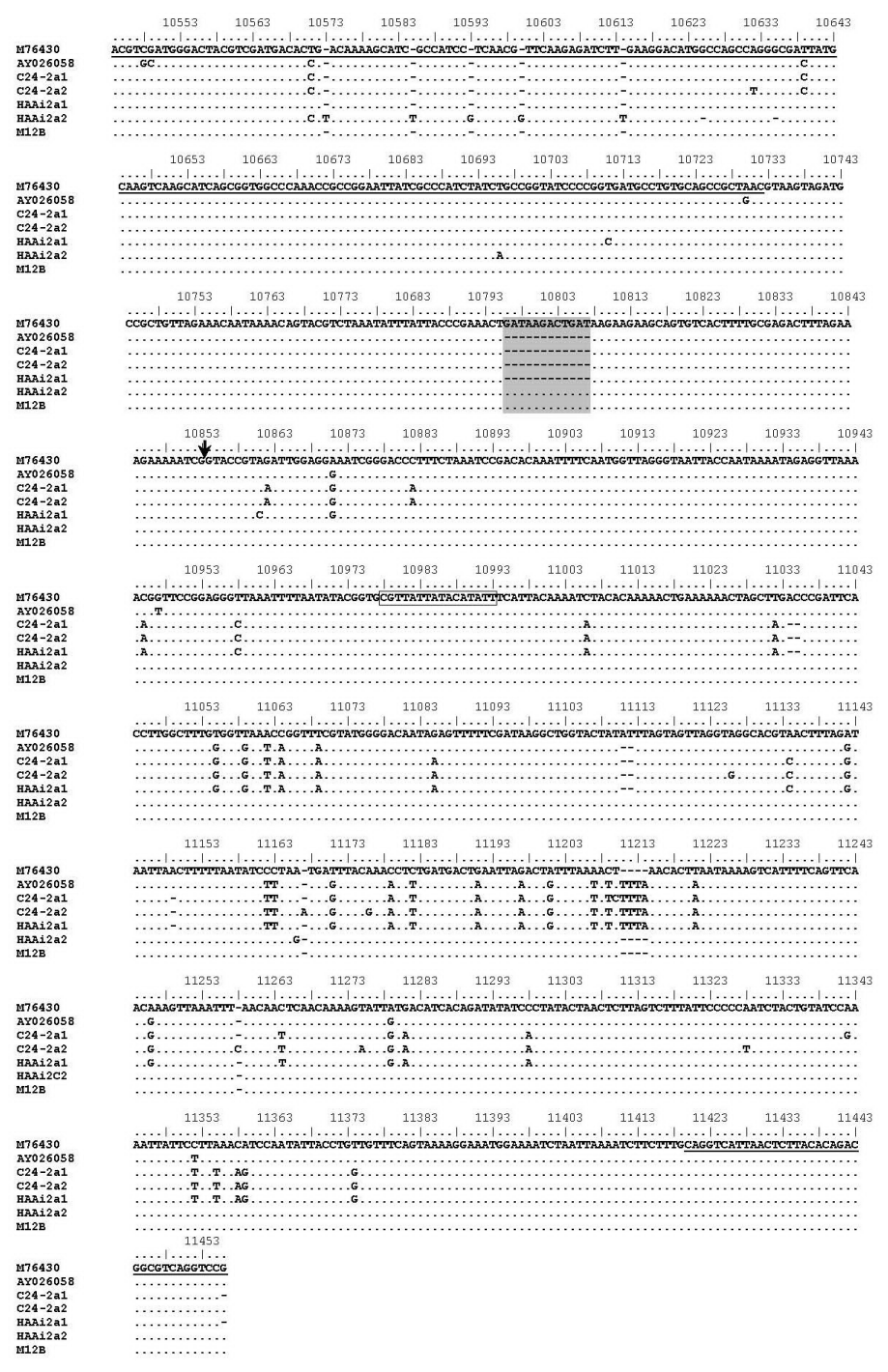

Figure 5. ClustalW alignment of the Bombyx mori fib- $L$ gene third intron sequences. The C24-2 and HAAi2 strains show two allele sequences (a1 and a2). In the 5' and 3' ends, exons three and four are underlined. The KpnI site is indicated by the arrow (position 10,853). The sequence of the $16 \mathrm{bp}$ in the $N d-s^{D}$ mutation is shown in the box and the polymorphic sequence with $12 \mathrm{bp}$ is shadowed in gray. M76430 is a Japanese strain and AY026058 is a Chinese one. 
The allele cloned from the M12B strain had a sequence similar to that of the Japanese M76430. However, the heteroduplex DNA molecules observed from the 600-bp fragment in Figure 4 were identical to those shown for the C24-2 strain, which suggests that the other allele present in the M12B population had nucleotide alterations in this fragment, as observed in the C24-2 alleles.

Sequence analysis helped in the understanding of the heteroduplex DNA molecule profiles observed in the REF-CSGE and showed that it is possible to analyze the variability of the third intron of the fib- $L$ gene using this method. The alignment results of the sequences also showed that this intron has several conserved segments. One of these segments includes the 16-bp sequence (positions 10,978 to 10,993), which is found to be duplicated in the $N d-s^{D}$ mutation (Gamo and Sato, 1985).

The results shown here are important because there are few studies on $f i b-L$ gene polymorphism. Kikuchi et al. (1992) described that there are considerable restriction-fragment length polymorphisms in regions containing the first intron and the 3 ' flanking sequence of the $f i b-L$ gene, which was observed when the restriction pattern of the J-139 strain was compared amongst eight $B$. mori breeds that produce normal levels of fibroin. However, the sizes of the $f i b-L$ mRNA and polypeptide were very similar, although the polymorphism may not influence protein production; this can alter the potential structure and stability of DNA. Sequence analysis showed that this intron has several conserved regions, mainly in the segment involved in the $N d-s^{D}$ mutation in the $f i b-L$ gene. Recently, our research group demonstrated that this segment has an alternative DNA structure that could be involved in DNA duplication and breakage for the establishment of this mutation (Barbosa et al., 2008).

In summary, the CSGE and REF-CSGE analyses allowed the detection of allelic variability among the B. mori strains studied here. The determination of two heteroduplex DNA molecule profiles, in combination with REF-CSGE, is useful in the identification of allelic variability. These results can be used as a guide to characterize all silkworm strains of the germplasm bank from UEM/ACESP.

\section{ACKNOWLEDGMENTS}

The authors would like to thank Valmir Peron and Marli Licero Schuete Silva for their dedicated technical assistance, as well as the Universidade Estadual de Maringá facilities (COMCAP laboratories). Research supported by grants from FINEP/Fundação Araucária, Secretaria de Estado da Ciência, Tecnologia e Ensino Superior, SETI, FUNDO PARANA and the Science and Innovation Santander Banespa 2006 Prize.

\section{REFERENCES}

Barbosa JF, Bravo JP, Takeda KI, Zanatta DB, et al. (2008). Intrinsic bent DNA colocalizes with the sequence involved in the Nd-s mutation in the Bombyx mori fibroin light chain gene. BMB Rep. 41: 394-399.

Finnilä S, Hassinen IE, la-Kokko L and Majamaa K (2000). Phylogenetic network of the mtDNA haplogroup U in Northern Finland based on sequence analysis of the complete coding region by conformation-sensitive gel electrophoresis. Am. J. Hum. Genet. 66: 1017-1026.

Gamo T and Sato S (1985). Ultrastructural study of the posterior silk gland in the $N d, N d-s^{D}$ mutants with a defect of fibroin synthesis. J. Seric. Sci. Jpn. 54: 412-419.

Ganguly A (2002). An update on conformation sensitive gel electrophoresis. Hum. Mutat. 19: 334-342. 
Ganguly A, Rock MJ and Prockop DJ (1993). Conformation-sensitive gel electrophoresis for rapid detection of singlebase differences in double-stranded PCR products and DNA fragments: evidence for solvent-induced bends in DNA heteroduplexes. Proc. Natl. Acad. Sci. U. S. A. 90: 10325-10329.

Goldsmith MR, Shimada T and Abe H (2005). The genetics and genomics of the silkworm, Bombyx mori. Annu. Rev. Entomol. 50: 71-100.

Herzog JS, Jancis EM, Liao S, Somlo G, et al. (2002). Restriction endonuclease fingerprinting enhanced conformation sensitive gel electrophoresis (REF-CSGE) in the analysis of BRCA1 exon 11 mutations in a high-risk breast cancer cohort. Hum. Mutat. 19: 656-663.

Inoue S, Tanaka K, Arisaka F, Kimura S, et al. (2000). Silk fibroin of Bombyx mori is secreted, assembling a high molecular mass elementary unit consisting of H-chain, L-chain, and P25, with a 6:6:1 molar ratio. J. Biol. Chem. 275: 40517-40528.

Karppinen SM, Erkko H, Reini K, Pospiech H, et al. (2006). Identification of a common polymorphism in the TopBP1 gene associated with hereditary susceptibility to breast and ovarian cancer. Eur. J. Cancer 42: 2647-2652.

Kikuchi Y, Mori K, Suzuki S, Yamaguchi K, et al. (1992). Structure of the Bombyx mori fibroin light-chain-encoding gene: upstream sequence elements common to the light and heavy chain. Gene 110: 151-158.

Körkkö J, Kaitila I, Lonnqvist L, Peltonen L, et al. (2002). Sensitivity of conformation sensitive gel electrophoresis in detecting mutations in Marfan syndrome and related conditions. J. Med. Genet. 39: 34-41.

Krawczynski MR, Czarny-Ratajczak M, Pecold K and Latos-Bielenska A (2004). Only neutral polymorphisms found in the TIGR/myocilin gene of 45 Polish patients with primary open-angle glaucoma. J. Appl. Genet. 45: 275-279.

Lahti M, Marttila R and Hallman M (2004). Surfactant protein C gene variation in the Finnish population - association with perinatal respiratory disease. Eur. J. Hum. Genet. 12: 312-320.

Li M, Shen L, Xu A, Miao X, et al. (2005). Genetic diversity among silkworm (Bombyx mori L., Lep., Bombycidae) germplasms revealed by microsatellites. Genome 48: 802-810.

Mills DR and Goldsmith MR (2000). Characterization of early follicular cDNA library suggests evidence for genetic polymorphisms in the inbred strain C108 of Bombyx mori. Genes Genet. Syst. 75: 105-113.

Mori K, Tanaka K, Kikuchi Y, Waga M, et al. (1995). Production of a chimeric fibroin light-chain polypeptide in a fibroin secretion-deficient naked pupa mutant of the silkworm Bombyx mori. J. Mol. Biol. 251: 217-228.

Ohmachi T, Nagayama H and Shimura K (1982). The isolation of a messenger RNA coding for the small subunit of fibroin from the posterior silkgland of the silkworm, Bombyx mori. FEBS Lett. 146: 385-388.

Reagan TE and Flynn JL (1986). Insect Pest Management of Sweet Sorghum in Sugarcane Production Systems of Louisiana: Problems and Integration. In: Biomass Energy Development (Smith WH, ed.). Plenum, New York, 237-239.

Sundaresan S, Eapen CE, Shaji RV, Chandy M, et al. (2007). Screening for mutations in ATP7B gene using conformationsensitive gel electrophoresis in a family with Wilson's disease. Med. Sci. Monit. 13: CS38-CS40.

Takei F, Kikuchi Y, Kikuchi A, Mizuno S, et al. (1987). Further evidence for importance of the subunit combination of silk fibroin in its efficient secretion from the posterior silk gland cells. J. Cell Biol. 105: 175-180.

Velasco E, Infante M, Duran M, Perez-Cabornero L, et al. (2007). Heteroduplex analysis by capillary array electrophoresis for rapid mutation detection in large multiexon genes. Nat. Protoc. 2: 237-246.

Vianello F, Lombardi AM, Dal Bello F, Zanon E, et al. (2002). Conformation sensitive gel electrophoresis for detection of factor X gene mutations. Thromb. Res. 107: 51-54.

Yamaguchi K, Kikuchi Y, Takagi T, Kikuchi A, et al. (1989). Primary structure of the silk fibroin light chain determined by cDNA sequencing and peptide analysis. J. Mol. Biol. 210: 127-139.

Yasukochi Y (1998). A dense genetic map of the silkworm, Bombyx mori, covering all chromosomes based on 1018 molecular markers. Genetics 150: 1513-1525. 